\title{
ALTERAÇÕES MORFOLÓGICAS EM TRAQUÉIAS DE PACIENTES INTUBADOS EM FUNÇÃO DO TEMPO DE INTUBAÇÃO
}

Barbosa PMK, Santos BMO. Alterações morfológicas em traquéias de pacientes intubados em função do tempo de intubação. Rev Latino-am Enfermagem 2003 novembro-dezembro; 11(6):727-33.

Este é um estudo, de caráter analítico-descritivo, que teve como objetivo descrever as alterações morfológicas da traquéia de pacientes intubados com cânulas de alto volume residual e baixa pressão no "cuff", mantidos em ventilação mecânica com pressão intra -"cuff" menor que a capilar da traquéia (20 a $30 \mathrm{mmHg}$ ), em função do tempo de intubação. A população constou de 23 pacientes adultos, internados em uma UTI, intubados por períodos entre 27 a 317 horas, e que foram a óbito, necessitando de necropsia para identificação da causa mortis. As alterações encontradas limitaram-se apenas à mucosa da traquéia, atingindo somente o epitélio de revestimento e a lâmina própria, e o tempo de intubação foi um fator determinante do agravamento das lesões na parede traqueal.

DESCRITORES: intubação intratraqueal; complicações; pressão do ar

\section{MORPHOLOGIC TRACHEA ALTERATIONS IN INTUBATED PATIENTS IN FUNCTION OF INTUBATION TIME}

This is a descriptive analytic study which aimed to describe the morphologic alterations of the trachea in intubated patients with cannulas of high-residual volume and low-pressure cuff, maintained on mechanical ventilation with lower pressure inside the "cuff" than the tracheal capillary pressure $(20-30 \mathrm{mmHg})$ in function of intubation time. The study population consisted of 23 adult patients admitted at an Intensive Care Unit, who were intubated for periods ranging from 27 to 317 hours and died, needing necropsy to identify the cause of deaths. The observed alterations were limited to the tracheal mucous membrane, affecting only the epithelium tissue and the lamina propria. Intubation time was a determinant factor to aggravate tracheal wall injuries.

DESCRIPTORS: intratracheal intubation; complications; air pressure

\section{ALTERACIONES MORFOLÓGICAS EN TRAQUEAS DE PACIENTES INTUBADOS EN RELACIÓN CON EL TIEMPO DE INTUBACIÓN}

Este es un estudio de carácter descriptivo que tuvo como objetivo describir las alteraciones morfológicas de la traquea de los pacientes intubados con cánulas de alto volumen residual y baja presión en el "cuff" , mantenidos en ventilación mecánica con presión intra - "cuff" menor que la capilar de la traquea (20 a $30 \mathrm{mmHg}$ ) en función del tiempo de intubación. La población constó de 23 pacientes adultos internados en una UCl, intubados por periodos entre 27 a 317 horas y que luego del fallecimiento se les realizó autopsia para identificar la causa de la muerte. Las alteraciones encontradas se limitaron a la mucosa de la traquea, afectando solamente el epitelio de revestimiento y la lámina propia; el tiempo de intubación fue un factor determinante de agravación de las lesiones en la pared traqueal.

DESCRIPTORES: intubación endotraqueal; complicaciones; presión del aire

\footnotetext{
${ }^{1}$ Professor Doutor da Faculdade de Medicina de Marília, e-mail: karan@famema.br; ${ }^{2}$ Professor Livre-Docente da Escola de Enfermagem de Ribeirão Preto, da Universidade de São Paulo, Centro Colaborador da OMS para o desenvolvimento da pesquisa em enfermagem, Orientador
} 
APRESENTAÇÃO

$\boldsymbol{U}_{\text {ma situação que tem despertado nosso }}$ interesse é a observação de condutas inadequadas na execução do procedimento de intubação endotraqueal, capazes de desencadear, e até de perpetuar, lesões traqueais e pulmonares que podem comprometer significativamente a recuperação dos pacientes.

Em diversas situações, temos nos deparado com evidências de uma prática empírica de intubação, com profissionais preocupados em apenas livrar os pacientes dos riscos de aspiração e hipóxia causados pelo vazamento de ar pela traquéia, sem atentar para os riscos advindos do aumento da pressão do "cuff" na mucosa, em conseqüência da hipersuflação do balonete.

Outra observação tem sido a de que os pacientes submetidos a intubação endotraqueal, com vistas à manutenção da permeabilidade das vias aéreas, permanecem intubados por longos períodos de tempo, sem uma avaliação dos possíveis danos na parede da traquéia.

Essas constatações despertaram o nosso interesse em desenvolver este estudo, com o objetivo de descrever as alterações morfológicas da traquéia de pacientes intubados com cânulas endotraqueais de alto volume residual e baixa pressão no "cuff", mantidos em ventilação mecânica com pressão intra - "cuff" menor que a capilar da traquéia (20 a 30 $\mathrm{mmHg}$ ), em função do tempo de intubação.

\section{MARCOS DE REFERÊNCIA}

Em termos estruturais, a traquéia é constituída por três camadas: mucosa, submucosa e adventícia. A mucosa é constituída pelo epitélio respiratório, lâmina própria e lâmina elástica. O epitélio respiratório ou de revestimento, do tipo pseudo estratificado colunar ciliado, é constituído por seis tipos celulares: células colunares ciliadas (distribuídas por todas as vias de condução do trato respiratório e que movimentam o muco por ação ciliar), células caliciformes (produzem secreção mucosa que se adiciona à das glândulas localizadas na submucosa), células serosas (possuem microvilos e estão relacionadas com a secreção de um fluido seroso de composição desconhecida), células em escova (apresentam numerosos microvilos em suas superfícies apicais e têm sido associadas com terminações nervosas, com provável função sensorial), células basais (situadas sobre a lâmina basal, consideradas como células fonte que repõem células caliciformes, células colunares ciliadas e células em escova) e, finalmente, células granulares (atuam como efetoras na integração das secreções mucosa e serosa $)^{(1-3)}$.

Ainda, segundo os autores, a lâmina própria é constituída por tecido conjuntivo frouxo fibroelástico, contém elementos linfóides e glândulas mucosas e seromucosas, cujos ductos abrem-se na superfície epitelial, e uma densa camada de fibras elásticas, que constitui a lâmina elástica, que separa a lâmina própria da submucosa subjacente. A submucosa é composta por tecido conjuntivo denso, irregular, fibroelástico, onde se encontram numerosas glândulas mucosas e seromucosas e elementos linfóides. A camada adventícia é composta por tecido fibroelástico, e sua característica mais importante são os anéis em forma de "C", de cartilagem hialina, com tecido conjuntivo fibroso interposto, sendo responsável por ancorar a traquéia às estruturas adjacentes.

O conhecimento dessa estrutura torna-se importante quando da necessidade do procedimento de intubação endotraqueal, que subentende a colocação translaringeana de uma cânula dentro da traquéia, por meio do nariz (intubação nasotraqueal) ou da cavidade oral (intubação orotraqueal), por um tempo determinado, com vistas a suprir as necessidades de manutenção da permeabilidade das vias aéreas, aspiração de secreções pulmonares, ventilação com pressão positiva e manutenção de oxigênio ${ }^{(4-6)}$.

A cânula endotraqueal mais indicada para a realização do procedimento tem sido a de alto volume residual e baixa pressão, por causar menos complicações, desde que seu diâmetro seja adequado ao diâmetro da traquéia $^{(7-8)}$. O seu balonete acomoda um grande volume de ar insuflado antes de aumentar a sua pressão que, segundo vários autores ${ }^{(6-9)}$, deve ficar entre 20 e $25 \mathrm{mmHg}$, pressão esta menor que a capilar traqueal (25 a 30 $\mathrm{mmHg}$ ), de modo a impedir a aspiração pulmonar, permitir o fluxo sangüíneo capilar adequado à mucosa da mesma e minimizar outras complicações como dilatação da traquéia, inflamação da mucosa, ulceração dos anéis cartilaginosos, infecção e destruição da parede traqueal, dentre outras. Os autores consideram, ainda, a influência do tempo de intubação nas possíveis lesões da parede traqueal. 
Nesse sentido, algumas pesquisas foram realizadas com vistas a estudar essa relação, isto é, o tempo de intubação, com as lesões ocasionadas pelo balonete das cânulas endotraqueais, tanto em humanos como em animais. Seus resultados, ainda que advindos de tempos de intubação e de condições clínicas variáveis, evidenciaram processo inflamatório difuso associado a extensas áreas de necrose em laringe e traquéia, extensas áreas de necrose na traquéia, abrangendo o epitélio e a lâmina própria ${ }^{(10-11)}$, perda de cílios, presença de células inflamatórias, áreas sugestivas de metaplasia escamosa $^{(12)}$, erosão parcial e total da parede traqueal ${ }^{(13)}$ presença de áreas hemorrágicas na submucosa, perda de cílios, perda de células caliciformes, erosão e inflamação ${ }^{(14)}$ e áreas de erosão e necrose epitelial, processo inflamatório difuso associado a extensas áreas de necrose ${ }^{(15)}$.

Vale considerar, também, as observações de autores que consideraram o aumento do risco de lesão em pacientes intubados, com necessidade de ventilação assistida controlada, devido à umidificação inadequada, concentração inadequada de oxigênio ( $\mathrm{FiO} 2)$, falta de aquecimento adequado da nebulização do ventilador mecânico (30 a $37^{\circ} \mathrm{C}$ ), alteração da fisiologia neuronal normal, introdução de material estranho na traquéia (cateter de aspiração) e tempo de utilização dos respiradores $^{(13-14,16-17)}$.

\section{MATERIAL E MÉTODOS}

População do estudo

Fizeram parte do estudo 23 pacientes adultos (acima de 15 anos), de ambos os sexos, internados na Unidade de Terapia Intensiva (U.T.I.) do Hospital de Clínicas de Marília, num período de tempo variável de até 13 dias, intubados com cânulas endotraqueais de alto volume residual e baixa pressão, mantidas com pressão intra "cuff" de 20 a $30 \mathrm{mmHg}$, independente do diagnóstico médico, e que foram a óbito durante a permanência na unidade, tendo sido submetidos a necropsia, por indicação médica.

Procedimento

Após aprovação do projeto pelo Comitê de Ética em Pesquisa do hospital, confirmação da necropsia pelo médico e obtenção da assinatura do termo de consentimento pós-informação pelos familiares, as traquéias foram retiradas e imediatamente acondicionadas em frasco contendo formol a 10\% para fins de fixação, encaminhadas ao setor de Patologia, onde foram submetidas a uma incisão na parede posterior, para análise macroscópica com vistas à detecção de possíveis alterações advindas do contato do balonete com a mucosa delas. Após a referida análise, foram retirados os segmentos que haviam permanecido sob pressão do "cuff".

Os referidos segmentos foram mantidos imersos em solução de formol a 10\%, por, no mínimo, 24 horas, lavados em água corrente por igual tempo, desidratados com soluções de álcool crescentes (70\%, 90\% e absoluto), por 90 minutos em cada solução, e diafanizados em solução de Xilol. A seguir, foram impregnados e incluídos em parafina, e cortados com cinco micrômetros de espessura. Os cortes histológicos eram montados em lâminas de vidro, corados com Hematoxilina-Eosina e, posteriormente, submetidos à análise microscópica para a detecção de possíveis alterações advindas do contato do balonete com a mucosa.

A análise histológica foi realizada pelo pesquisador, em conjunto com um histologista e um patologista, docentes da FAMEMA, por meio de microscopia ótica (de luz) que determina a riqueza de detalhes da imagem por meio de seu limite de resolução (capacidade de oferecer detalhes) e não de seu poder de aumentar o tamanho dos objetos. Essa análise visava à obtenção da descrição das possíveis alterações estruturais da traquéia que ficou sob pressão do "cuff" das cânulas endotraqueais (mucosa, submucosa e adventícia) e não à das estruturas das células (organelas, membranas, citoesqueleto, inclusões) que constituem esses tecidos.

\section{RESULTADOS E DISCUSSÃO}

Dos 23 pacientes do estudo, 14 (60,9\%) eram do sexo masculino, e 9 (39,1\%), do feminino (Tabela 1). Ao relacionarmos o sexo com a faixa etária, observamos que todos os pacientes entre 15 a 30 anos $(17,4 \%)$ eram do sexo feminino, e os entre 30 a 40 anos (4,3\%), do sexo masculino; nos entre 40 a 50 anos, a porcentagem foi a mesma para ambos os sexos (13,0\%); naqueles com idades acima de 50 anos, houve predominância do sexo 
masculino (39,2\%), e um paciente do sexo masculino tinha idade ignorada. O tempo de intubação variou de 27 a 317 horas, correspondendo a um período de internação de até 13 dias. Vale considerar que, no período de tempo de 55 a 80 horas, não tivemos pacientes para nossa coleta de dados.

Tabela 1 - Distribuição dos pacientes intubados, segundo o sexo e a faixa etária

\begin{tabular}{ccccccccc}
\hline \multirow{2}{*}{ Faixa Etária } & \multicolumn{3}{c}{ Masculino } & \multicolumn{2}{c}{ Feminino } & \multicolumn{3}{c}{ Total } \\
& & & № & $\%$ & № & $\%$ & № & $\%$ \\
\hline 15 & --- & 30 & - & - & 4 & 17,4 & 4 & 17,4 \\
30 & --- & 40 & 1 & 4,3 & - & - & 1 & 4,3 \\
40 & --- & 50 & 3 & 13,0 & 3 & 13,0 & 6 & 26,0 \\
50 & --- & 60 & 5 & 21,8 & 1 & 4,3 & 6 & 26,0 \\
60 & --- & + & 4 & 17,4 & 1 & 4,3 & 5 & 21,7 \\
Ignorada & & & 1 & 4,3 & - & - & 1 & 4,3 \\
\hline Total & & & $\mathbf{1 4}$ & $\mathbf{6 0 , 9}$ & $\mathbf{9}$ & $\mathbf{3 9 , 1}$ & $\mathbf{2 3}$ & $\mathbf{1 0 0 , 0}$ \\
\hline
\end{tabular}

A análise macroscópica possibilitou a visualização de alterações caracterizadas por coloração diferenciada no local que permaneceu em contato com o "cuff", zonas hemorrágicas e escoriações, em contraste com o restante do segmento traqueal que não permaneceu sob pressão.

A análise microscópica evidenciou alterações apenas na mucosa, constituída pelo epitélio respiratório, lâmina própria e lâmina elástica, mais especificamente no epitélio de revestimento e lâmina própria, não chegando a atingir a lâmina elástica. As alterações do epitélio de revestimento caracterizaram-se como perda de cílios, exulceração, metaplasia escamosa, infiltrado polimorfonuclear (focal e difuso), hiperplasia celular, necrose celular (morte celular, com ou sem infiltrado inflamatório) e erosão (perda do epitélio de revestimento). $\mathrm{Na}$ lâmina própria, foram identificados infiltrado polimorfonuclear (linfomonocitário, neutrofílico e plasmocitário) e hemorragia. Essas alterações foram identificadas de forma isolada ou simultaneamente $\mathrm{e}, \mathrm{a}$ título de ilustração, estão apresentadas nas Tabelas 2, 3 e 4, na tentativa de ilustrar a associação entre as alterações identificadas e o tempo de intubação, bem como a sua localização no epitélio de revestimento e na lâmina própria, respectivamente.

Tabela 2 - Alterações microscópicas na mucosa das traquéias, segundo o tempo de intubação endotraqueal e número de pacientes

\begin{tabular}{|c|c|c|}
\hline $\begin{array}{l}\text { Tempode } \\
\text { in tubação }\end{array}$ & $\begin{array}{c}N=\text { de } \\
\text { pacientes }\end{array}$ & A Iterações m icroscópicas \\
\hline & & $\begin{array}{l}\text {-A usência de cílios nas células colunares e presença de áreas focais de } \\
\text { exulceração no epitélio de revestimento. }\end{array}$ \\
\hline 24 a 55 horas & 4 & $\begin{array}{l}\text { - Difuso infiltrado polimorfonuclear na lâmina própria. } \\
\text { - Hiperplasia celular, ausência de cílios nas células colunares, presença de } \\
\text { áreas focais de exulceração e infiltrado polimorfonuclear no epitélio de }\end{array}$ \\
\hline 80 a 105 horas & 1 & $\begin{array}{l}\text { revestimento. } \\
\text { - Infiltrado neutrofílico difuso na lâm ina própria. } \\
\text { - Áreas extensas de exulceração, com presença da camada basal e áreas } \\
\text { focais de regeneração, caracterizadas pela presença de células basais, com }\end{array}$ \\
\hline 105 a 130 horas & 4 & $\begin{array}{l}\text { nucléolo proemine nte no epitélio de revestim ento. } \\
\text {-Na lâm ina própria: difuso infiltrado polimorfonuclear e áreas hemorrágicas. } \\
\text {-Extensas áreas de exulceração e regiós de necrose com restos celulares e } \\
\text { ausência de infiltrado inflam atório no epitélio de revestimento. }\end{array}$ \\
\hline 130 a 155 horas & 5 & $\begin{array}{l}\text { - Difuso infiltrado polimorfonuclear e áreas hemorrágicas na lâmina própria. } \\
\text {-Epitélio de revestimento: erosão focal, com perda total do epitélio de } \\
\text { revestimento, com predomínio de extensas áreas de exulceração. }\end{array}$ \\
\hline 155 a 180 horas & 3 & $\begin{array}{l}\text { - Difuso infiltrado polimorfonuclear e discretas áreas hemorrágicas na lâm ina } \\
\text { própria. } \\
\text { - Epitélio de revestimento com algumas regiões constituídas por células } \\
\text { alongadas e achatadas, sugestivas de metaplasia escamosa, com } \\
\text { predom ínio de áreas de exulceração presença de poucas células basais. } \\
\text { - Presença de exsudato fibrino-neutrofílico-linfocitário e áreas hemorrágicas } \\
\text { focais na lâm ina própria. }\end{array}$ \\
\hline 205 a 230 horas & 1 & $\begin{array}{l}\text { - Hiperplasia celular e ausência de cílios nas células colunares do epitélio de } \\
\text { revestimento. } \\
\text { - Infiltrado linfoplasmocitário denso, de aspecto nodular, na lâm ina própria. } \\
\text { - Algumas regiões do epitélio de revestimento com erosão focal, outras com } \\
\text { metaplasia escamosa e predomínio de extensas áreas de exulceração, com }\end{array}$ \\
\hline 230 a 255 horas & 1 & $\begin{array}{l}\text { poucas células basais. } \\
\text { - Na lâm ina própria, infiltrado polimorfonuclear moderadamente denso. } \\
\text {-Epitélio de revestimento com erosão focal, metaplasia escamosa e, } \\
\text { predom inantemente, áreas de exulceração. }\end{array}$ \\
\hline 255 a 280 horas & 1 & $\begin{array}{l}\text {-Infiltrado polimorfonuclear difuso na lâm ina própria. } \\
\text {-Extensas áreas de erosão no epitélio de revestimento. }\end{array}$ \\
\hline $\mathrm{M}$ a is de $280 \mathrm{ho}$ & 1 & ros linfócitos e raros plasmócitos na lâm ina própria. \\
\hline
\end{tabular}


Tabela 3 - Alterações microscópicas no epitélio respiratório das traquéias, em função do tempo de intubação endotraqueal

\begin{tabular}{|c|c|c|c|c|c|c|c|c|c|c|}
\hline \multirow{2}{*}{ Alterações } & \multicolumn{10}{|c|}{ Tempo de intubação (em horas) } \\
\hline & $24 \mid--55$ & $80 \mid--105$ & $105 \mid--130$ & $130 \mid--155$ & $155 \mid--180$ & $180 \mid--205$ & $205 \mid-230$ & $230 \mid-255$ & $255 \mid-280$ & $280 \mid-+$ \\
\hline Perda de cílios & $x$ & $x$ & $\mathrm{x}$ & $x$ & $x$ & $x$ & $x$ & $x$ & $x$ & $x$ \\
\hline $\begin{array}{c}\text { Infiltrado } \\
\text { polimorfonuclear }\end{array}$ & & $x$ & & $x$ & & & & & & \\
\hline $\begin{array}{l}\text { Hiperplasia } \\
\text { celular }\end{array}$ & & $x$ & & & & & $x$ & & & \\
\hline Exulceração & $x$ & $x$ & $x$ & $x$ & $x$ & $x$ & & $x$ & $x$ & \\
\hline Necrose celular & & & & $x$ & & & & & & \\
\hline $\begin{array}{l}\text { Metaplasia } \\
\text { escamosa }\end{array}$ & & & & & & $x$ & & $x$ & $x$ & \\
\hline Erosão & & & & & $\mathrm{x}$ & & & $\mathrm{x}$ & $\mathrm{x}$ & $\mathrm{x}$ \\
\hline
\end{tabular}

Tabela 4 - Alterações microscópicas na lâmina própria das traquéias, em função do tempo de intubação endotraqueal

\begin{tabular}{|c|c|c|c|c|c|c|c|c|c|c|}
\hline \multirow{2}{*}{ Alterações } & \multicolumn{10}{|c|}{ Tempo de intubação (em horas) } \\
\hline & $24 \mid-55$ & $80 \mid-105$ & $105 \mid-130$ & $130 \mid-155$ & $155 \mid--180$ & $180 \mid--205$ & $205 \mid-230$ & $230 \mid-255$ & $255 \mid-280$ & $280 \mid-+$ \\
\hline $\begin{array}{c}\text { Infiltrado } \\
\text { polimorfonuclear }\end{array}$ & $x$ & $x$ & $x$ & $x$ & $x$ & $x$ & $x$ & $x$ & $x$ & $x$ \\
\hline Hemorragia & & & $x$ & $x$ & $x$ & $x$ & & & & \\
\hline
\end{tabular}

Vários autores descrevem a perda de cílios, observada em todos os segmentos das traquéias analisadas, em função do próprio ato de intubação. Um deles $^{(8)}$ relata que somente a passagem do tubo endotraqueal já é suficiente para ocasionar a destruição dos cílios e das células do epitélio de revestimento traqueal. Ressalta, ainda, que o tempo de intubação é um fator determinante dessa complicação, ou seja, que, quanto maior o tempo, maior a gravidade do caso e que, mesmo com duas horas de intubação, com o balonete insuflado ou não, os cílios já ficam achatados e esmagados, com possível regeneração após duas horas de extubação.

Num estudo com traquéias de cães e humanos ${ }^{(12)}$, intubados com pressão no "cuff" de 18 a 25 mmHg, por curto período (duas a 12 horas), os autores identificaram, nos cães, alterações como perda de cílios e presença de células inflamatórias na região que permaneceu em íntimo contato com a pressão do balonete, e, nos humanos, áreas sugestivas de metaplasia escamosa, caracterizadas por células achatadas, ocorrendo regeneração ciliar primitiva após 48 horas.

Outro estudo, objetivando avaliar os efeitos imediatos da intubação (após quatro horas), com cânulas de alto volume residual e baixa pressão, por meio de cortes histológicos de laringe e traquéia de cães intubados ${ }^{(18)}$,detectou a ocorrência de alterações nas superfícies livres das células ciliadas do epitélio de revestimento laringotraqueal, o que compromete o seu funcionamento ciliar normal.

A perda de cílios, em toda extensão da traquéia de ratos intubados com cânulas endotraqueais sem "cuff", também foi registrada ${ }^{(15)}$, e alguns autores ${ }^{(13-14,16-17)}$, dentre outros, consideram que a intubação endotraqueal e a ventilação mecânica aumentam o risco de lesões traqueais, como perda de células caliciformes e até perda parcial e total do epitélio de revestimento, em decorrência do uso de material estranho na traquéia, pressão do "cuff" na parede endotraqueal, umidificação inadequada, concentração elevada de oxigênio, falta de aquecimento do ar inalado, alteração da fisiologia neuronal e tempo de utilização dos respiradores.

A necessidade de manter a pressão do balonete abaixo de $30 \mathrm{mmHg}$ tem sido reforçada, e as variações de pressão (acima $32 \mathrm{mmHg}$ ) têm sido relacionadas a variadas complicações, que vão desde a oclusão do fluxo sangüíneo na mucosa, destruição do epitélio de revestimento, até ulceração, dilatação, ruptura e estenose $^{(19-21)}$.

Algumas dessas complicações foram 
identificadas em traquéias de nosso estudo. A exulceração do epitélio de revestimento, caracterizada por uma destruição parcial de suas células, foi identificada em diferentes tempos de intubação, desde o menor (27 horas) até 275 horas. Áreas de perda total do epitélio de revestimento (erosão) foram localizadas nas traquéias que permaneceram intubadas de 155 a 180 horas e naquelas com mais de 230 horas de intubação. A dilatação, ruptura e estenose da traquéia não apareceram em nenhum dos fragmentos examinados.

A influência da pressão do "cuff" nas alterações da mucosa da traquéia também tem sido associada ao tempo de intubação. A utilização de cânula endotraqueal, mesmo por curto período (duas horas), com o balonete insuflado ou não, pode causar alterações na mucosa endotraqueal, com conseqüências variáveis como dilatação, processo inflamatório com destruição ciliar, ulceração dos anéis cartilaginosos, infecção e até estenose ou ruptura, ocasionando danos por vezes irreversíveis ${ }^{(22-}$ 23).

Na análise dos nossos dados, pudemos constatar a identificação de apenas uma dessas alterações, no epitélio de revestimento: o processo inflamatório, caracterizado por infiltrado polimorfonuclear, em uma traquéia de paciente que permaneceu intubado por 103 horas. Na lâmina própria, esteve presente como infiltrado neutrofílico, em um paciente intubado pelo mesmo período e, na forma de associação dos diferentes tipos celulares, nas traquéias de outros oito (8) pacientes, com tempos variáveis de intubação. Vale considerar que as demais alterações citadas pelos autores (dilatação da traquéia, ulceração dos anéis cartilaginosos, infecção, estenose e ruptura) não foram identificadas nos pacientes de nosso estudo.

A exulceração do epitélio de revestimento, que compromete a proteção da traquéia, só não foi localizada nos pacientes cujas traquéias permaneceram sob pressão do "cuff" por 205 a 230 horas e por mais de 280 horas (um paciente para cada um dos tempos, respectivamente).

A necrose da traquéia, citada por alguns autores $^{(24-25)}$, ainda que não tenham feito dela nenhuma caracterização, foi identificada, em nosso estudo, como necrose celular do epitélio de revestimento, em apenas um dos cinco pacientes que permaneceram intubados por 130 a 155 horas. As áreas de erosão foram encontradas nas traquéias que permaneceram sob pressão, por períodos de até 155 horas ( 1 paciente), de 155 a 180 horas
(3 pacientes), e, em todos os demais, acima de 230 até 317 horas (3 pacientes).

A necrose também foi relatada, de forma isolada ou associada a outra alteração, em decorrência da intubação, pressão do "cuff" e tempo de intubação, por meio de cortes histológicos, em estudos envolvendo animais e seres humanos ${ }^{(6-7,10-12,15,26)}$

Outro estudo ${ }^{(12)}$ analisou as alterações na mucosa de traquéias de cães e humanos submetidos a intubação, mantidos em ventilação mecânica, com pressão no "cuff" entre 18 a $25 \mathrm{mmHg}$, por duas a 12 horas. Nos cães, foram detectadas perda de cílios e presença de células inflamatórias na região que permaneceu em íntimo contato com a pressão do balonete. Nos humanos, houve áreas sugestivas de metaplasia escamosa, caracterizadas por células achatadas.

As alterações identificadas nos cães foram encontradas em todos os segmentos das traquéias de nossa pesquisa. A alteração encontrada nos humanos, pelos autores, ou seja, a metaplasia escamosa, foi visualizada nos fragmentos de traquéias de quatro pacientes de nosso estudo (dois que permaneceram intubados de 180 a 205 horas, um que permaneceu por 246 horas, e outro por 275 horas).

A hemorragia, advinda do processo de intubação, foi citada dentre as alterações observadas nas traquéias de ratos, intubados com cânulas sem "cuff", por uma hora, dentre outras alterações como processo inflamatório, necrose e erosão epitelial. Ela foi localizada no epitélio de revestimento das referidas traquéias ${ }^{(15)}$. Nos humanos de nosso estudo, a alteração foi identificada na lâmina própria, em todos os pacientes que permaneceram intubados entre 105 a 205 horas (14 pacientes).

\section{CONCLUSÕES}

Com base nos achados acima apresentados, pontuamos que, apesar do controle da pressão do "cuff" (menor que a capilar da traquéia), foram observadas alterações nos seus segmentos:

- macroscopicamente, os segmentos das traquéias que permaneceram em contato com o balonete insuflado, apresentaram alterações caracterizadas por coloração diferenciada, zonas hemorrágicas e escoriações; - sob o ponto de vista microscópico, as alterações 
identificadas, em função do tempo de intubação, foram apenas na mucosa das traquéias, mais especificamente no epitélio de revestimento e lâmina própria;

- as alterações identificadas, isolada ou simultaneamente, foram perda de cílios, exulceração, metaplasia escamosa, infiltrado polimorfonuclear (linfocitário, neutrofílico e plasmocitário) focal e difuso, hiperplasia celular, necrose celular, erosão e hemorragia;

- a perda de cílios do epitélio de revestimento foi uma constante em todos os segmentos das traquéias;

- as alterações evidenciadas isoladamente foram exulceração, metaplasia escamosa, infiltrado polimorfonuclear, necrose celular e erosão, todas em nível

\section{REFERÊNCIAS BIBLIOGRÁFICAS}

1. Gartner LP, Hiatt JL. Tratado de histologia. Rio de Janeiro (RJ): Guanabara Koogan; 1999.

2. Junqueira LC, Carneiro J. Biologia celular e molecular. Rio de Janeiro (RJ): Guanabara Koogan; 1997.

3. Ross MH, Reith EJ, Romrell LJ. Histologia. São Paulo (SP): Panamericana; 1993.

4. Hudak CM, Gallo BM. Cuidados intensivos de enfermagem. Rio de Janeiro (RJ): Guanabara Koogan; 1997.

5. Bub FR, Avilla RM, Campos JRM. Intubação endotraqueal. In: Knobel E. Condutas no paciente grave. São Paulo (SP): Atheneu; 1999.

6. Stoelting RK. Intubação endotraqueal. In: Miller RD, editor. Tratado de anestesia. São Paulo (SP): Manole; 1989.

7. Stone DJ, Gal TJ. Manuseio das vias aéreas. In: Miller RD. Anestesia. São Paulo (SP): Artes Médicas; 1993.

8. Collins VJ. Princípios de anestesiologia. Rio de Janeiro (RJ): Guanabara Koogan; 1978.

9. Bandenhorst $\mathrm{CH}$. Changes in tracheal cuff pressure during respiratory support. Crit Care Med. 1987 April; 15(4):300-2.

10. Joshi VV, Mandavia SG, Stern L, Wiglesw FW. Acut lesion induced by endotracheal intubation: accurrence en the upper respiratory tract of newborn infants with respiratory distress syndrome. Am J Dis Child 1972; 124(5):646-9.

11. Rasche RF, Kuhns LR. Histopathologic changes in airway mucosa of infants afther endotracheal intubation. Pediatrics 1972; 50(4):632-7.

12. Klainer AS, Turndorf $\mathrm{H}$, WU WH, Maewal $\mathrm{H}$, Allender $\mathrm{P}$. Surface alterations due to endotracheal intubation. Am J Med 1975; 58(7):674-83.

13. Brodsky L, Naviwala S, Stanievich JFA. A quantitative comparison of the early histopathological change fron tracheotomy and andotracheal intubation on the distal trachea in fetal lambs. Int J Pediatr 1987; 12(3):273-82.

14. Wiswell TE, Turner BS, Bley JA, Fritz WL, Hunt RE. Determinants of tracheobronchial histologic alteration diring conventional mechanical ventilation. Pediatrics 1989; 84(2):304-11.

15. Squire R, Siddiqui ST, Dinunzio G, Brodsky L. Quantitative study of the early effects of tracheotomy and endotracheal intubation on the rabbit tracheobronchial tree. Ann Otol Rhinol Laryngol 1990; 99(1):62-8. do epitélio de revestimento;

- no epitélio de revestimento, foram identificadas, simultaneamente, exulceração, metaplasia escamosa, infiltrado polimorfonuclear (focal ou difuso) e erosão; - infiltrado polimorfonuclear (linfomonocitário, neutrofílico e plasmocitário) e as áreas de hemorragia foram identificadas na lâmina própria.

A apresentação dessas observações possibilitaram a conclusão de que as alterações encontradas limitaram-se apenas à mucosa da traquéia, atingindo somente o epitélio de revestimento e a lâmina própria, e o tempo de intubação foi um fator determinante do agravamento das lesões na parede traqueal.

16. Todd DA, John E, Osborn RA. Epithelial damage beyond the tip of the endotracheal tube. Early Hum 1990 dev; 24(3):187-200.

17. Mammel MC, Ophoven JP, Lewallen PK, Gordon MJ, Boros SJ. Acute airway injury during high frequency jet ventilation and high-frequency oscillatory ventilation. Crit Care Med 1991; 19(3):394-8

18. Schmidt WA, Schaap RN, mortensen JD. Immediate mucosal effects of short - term, soft-cuff, endotracheal intubation: a light and seanming electron microscopic study Arch Pathol. Lab Med 1979; 103(10):516-21.

19. Marjot R. Pressure exerted by the laryngeal mask airway cuff upon the pharyngeal mucosa. Br J Anesth $1993 \mathrm{Jan}$; 70(1):25-9.

20. Mehta S, Mickiewicz M. Pressure in large volume, low pressure cuffs: its significance, measurement and regulation. Intensive Care Med 1985 Dec; 11(5):267-72.

21. Mehta S. Tracheal tube cuff pressure (letter). Anaesthesia 1989 Dec; 44(12):1001-2.

22. Foulkes MR, Oulton JL. Complications of using cuffed endotracheal tubes (letter). Can Med Assoc J 1980 Jun; 123(6):486-7.

23. Bernhard WN, Yost L, Joynes D, Cothalis S, Turndorf H. Intracuff pressures in endotracheal and tracheostomy tubes: related cuff physical characteristics. Chest 1985 Jun; 87(6):720-5.

24. Strong RM, Passy V. Endotracheal intubation. Arch Otolarynngol 1977; 103(6):329-35.

25. Fan LL, Flynn JW, Pathak DR. Risk factors predicting laryngeal injury in intubated neonates. Crit Care Med 1983; 11(6):431-3.

26. Martins RHG, Braz JRC, Bretan O, Figueiredo PR, Defavire J. Lesões precoces da intubação endotraqueal. Rev Bras Otorrinolaringol 1995; 61(5):343-8. 